\title{
Dissolution Profile Evaluation of Solid Pharmaceutical Forms Containing Chloramphenicol Marketed in Brazil
}

\author{
Humberto Gomes Ferraz ${ }^{1 *}$, Leticia Norma Carpentieri ${ }^{2}$ and Sayuri Pereira Watanabe ${ }^{1}$ \\ ${ }^{1}$ Faculdade de Ciências Farmacêuticas; Universidade de São Paulo; Av. Lineu Prestes, 580; 05508-900; \\ sferraz@usp.br; São Paulo - SP - Brasil. ${ }^{2}$ Faculdade de Ciências Farmacêuticas; Universidade de Brasília; \\ Campus Darcy Ribeiro; 70910-900; Brasília - DF - Brasil
}

\begin{abstract}
The dissolution profile for solid pharmaceutical forms containing chloramphenicol 250 mg available in Brazil was determined using a method from the American Pharmacopoeia (United States Pharmacopoeia, 2004) and then compared. Two different methods of dissolution profile comparison were used: ANOVA, and an independent model. Differences between the formulations were reflected in the dissolution profiles. The presence of metastable polymorphs or amorphous forms of chloramphenicol palmitate might be responsible for variations in the concentration of the drug observed within formulations.
\end{abstract}

Key words: Chloramphenicol, Dissolution, Polymorphism

\section{INTRODUCTION}

Chloramphenicol is a large spectrum antibiotic with antimicrobial activity. Its mechanism of action is based on the inhibition of protein synthesis; however, the resistance of gram-positive and gram-negative microorganisms in vivo is a clinical problem of increasing importance (Kapusnik-Uner et al., 1996). Chloramphenicol is available for oral administration as chloramphenicol palmitate - a prodrug of chloramphenicol - developed with the objective of a more pleasent flavored derivative. Chloramphenicol palmitate is quickly and almost completely hydrolyzed by intestinal esterase, being distributed widely throughout corporal liquids and quickly achieving therapeutic levels (Singhal and Curatolo, 2004). Therapy with chloramphenicol should be limited to infections where the benefit of the drug exceeds the risk of potential toxicity (Kapusnik-Uner et al., 1996).

The absorption of drugs from solid pharmaceutical forms after oral administration depends, among other factors, on the liberation of the drug from the pharmaceutical form, its dissolution or solubility in physiological conditions, and its permeability through the gastrointestinal tract. Due to the critical nature of the two initial stages, dissolution tests in vitro can be relevant to predict the performance of the drug in vivo. Based on these considerations, dissolution tests are largely used to assure the quality of the pharmaceutical product. Methods for dissolution profile comparisons are suggested by SUPAC-IR (US, 1997).

Due to economical reasons, the use of generic medicines has been given much incentive by health authorities throughout the world. In Brazil, politics directed towards generic medicine was introduced in 1999 as an attempt to change the

* Author for correspondence 
national market. However, this can be problematic if the quality control and/or bioequivalence is not reached (Meredith, 1996).

The objective of this study was to the evaluate of the liberation in vitro (dissolution) of solid pharmaceutical forms containing chloramphenicol commercialized in Brazil.

\section{MATERIAL AND METHODS}

\section{Pharmaceutical Forms}

Two different brands containing $250 \mathrm{mg}$ of chloramphenicol palmitate in the form of filmcoated tablets (A, B), three different brands of 250 $\mathrm{mg}$ of chloramphenicol palmitate in the form of sugar coated tablets $(\mathrm{C}, \mathrm{D}, \mathrm{E})$ and three different brands containing $250 \mathrm{mg}$ of chloramphenicol palmitate in the form of capsules $(F, G$ and $H)$ were tested.

\section{Procedures}

Studies were performed using Hanson Research Corp. model SR-6 equipment. Samples were submitted to the dissolution test as is described by the American Pharmacopoeia (United States Pharmacopoeia, 2004) for chloramphenicol capsules (Table 1). Dissolution profiles were obtained under the same conditions. Aliquots $(10 \mathrm{~mL})$ were removed in $1,5,10,20,40$, and 60 minutes, and analyzed espectrophotometrically in $278 \mathrm{~nm}$ using a spectrophotometer Shimadzu model 1401. Aliquots from the dissolution medium without the drug (the same volume and the same temperature) were immediately added to the dissolution medium in order to maintain a constant volume during the test. Dissolution profiles were determinated by the USP XXVII methods to twelve units of dosage forms.

Table 1 - Conditions used for the dissolution test described by USP XXVII (2004) for chloramphenicol capsules.

$\begin{array}{cc}\text { Agitation System } & \text { Apparatus 1 (basquet) } \\ \text { Stirring rate } & 100 \mathrm{rpm} \\ \text { Dissolution medium } & \mathrm{HCl} 0.01 \mathrm{~N} \\ \text { Medium volume } & 900 \mathrm{~mL} \\ \text { Detection }(\text { method) } & \text { Spectrophotometer UV (278 nm) } \\ \text { Sampling time } & 30 \text { minutes }\end{array}$

\section{Statistical Analysis}

Comparison among dissolution profiles is recommended by the F.D.A (US, 1997). Two methods for dissolution profile comparisons were used: ANOVA and an independent comparison model. The parameter of dissolution efficiency (DE) was calculated using the dissolved percentage curves of the drug versus time, using the reason between the area above the curve (ASC) and the total area of the graph (surface), and expressed in percentage (Khan and Rodhes, 1975). The resulting DE values were submitted to statistical analysis using analysis variance (ANOVA) in order to detect the existence of significant differences between the respective lots. Following this procedure, an independent investigation model - Tukey test and the test of the minimal significant difference (MSD), was applied, dominating the multiple comparison tests. After the application of ANOVA, was possible to determine which products were considered similar (Bolton, 1990; Vieira, 1980).

\section{RESULTS AND DISCUSSION}

Sample quantification was based on a previously constructed calibration curve and submitted to a linear regression analysis. Linear relations were obtained with the concentration interval of 5-30 $\mu \mathrm{g} \cdot \mathrm{mL}^{-1}(\mathrm{r}=0.999504)$, according to the equation Abs $=-0.00683428+0.029437 \times \mathrm{C}\left(\mathrm{C}=\mu \mathrm{g} \cdot \mathrm{mL}^{-1}\right)$. Nowadays, the study of dissolution in vitro is considered a fundamental requirement in the pharmaceutical industry in order to assure the quality of solid pharmaceutical forms for oral use, guarantee the quality from lot to lot, orientate the development of new formulations and secure the uniformity quality and performance of the drug even after modifications. On a parallel basis, this allows formulation optimization in the development phase and, in the same way, it allows stability studies, manufacturing process monitoring, and the establishment of in vivo/in vitro correlations (Adams et al., 2001; Dressman et al., 1998; Skoug et al., 1996). 
The dissolution test, according to the American Pharmacopoeia (United States Pharmacopoeia, 2004), should obey the following criteria: in the first stage $\left(S_{1}\right)$, six tablets are tested, in such case that all are acceptable to the lot seeing that all tablets are within tolerance limits presented in the monograph $(\mathrm{Q}+5 \%)$. If the results are not in accordance with $S_{1}$, it is necessary to test six more tablets $\left(S_{2}\right)$. The tablet lot will be accepted if the average of the 12 tablets is greater or equal to $\mathrm{Q}$, and there are no units inferior to (Q-15\%). If the lot is rejected, test twelve more tablets $\left(\mathrm{S}_{3}\right)$ is needed, and if the average of all 24 tablets is greater or equal to $\mathrm{Q}$ and, if no more than 2 tablets present inferior results to $(\mathrm{Q}-15 \%)$, the lot is supposed to be a acceptable.

In the dissolution test for chloramphenicol tablets described in the American Pharmacopoeia (United States Pharmacopoeia, 2004), no less than $80 \%$ $(\mathrm{Q}+5 \%)$ should be dissolved in 30 minutes. The evaluated products $\mathrm{D}, \mathrm{G}$ and $\mathrm{H}$ evaluated did not fulfill the specifications in the first stage, seeing that after 30 minutes of testing the dissolution of both was inferior to $80 \%$ of the quantity declared on the label. Product $\mathrm{F}$ fulfilled the specifications only in the second stage, $S_{2}$ (Table 2).

Table 2 - Percentage values of dissolved chloramphenicol shown in mean (M), standard deviation (SD) and respective variation coefficients (VC), obtained for products $\mathrm{F}, \mathrm{G}$ and $\mathrm{H}$ on the dissolution test specified by United States Pharmacopoeia (2004).

\begin{tabular}{|c|c|c|c|c|}
\hline \multirow{3}{*}{ Vessels } & \multicolumn{4}{|c|}{ \% Dissolved } \\
\hline & \multicolumn{2}{|c|}{$F$} & \multirow[t]{2}{*}{$G$} & \multirow[t]{2}{*}{$\boldsymbol{H}$} \\
\hline & $S_{1}$ & $S_{2}$ & & \\
\hline 1 & 82.83 & 93.07 & 39.39 & 2.05 \\
\hline 2 & 84.66 & 89.86 & 31.75 & 1.93 \\
\hline 3 & 82.06 & 76.10 & 38.78 & 1.95 \\
\hline 4 & 77.94 & 79.01 & 65.07 & 1.81 \\
\hline 5 & 92.77 & 84.82 & 69.35 & 2.09 \\
\hline 6 & 71.21 & 83.75 & 68.74 & 3.15 \\
\hline $\mathrm{M}$ & \multicolumn{2}{|c|}{83.17} & 52.18 & 2.16 \\
\hline S.D. & \multicolumn{2}{|c|}{6.60} & 17.30 & 0.49 \\
\hline V.C. $(\%)$ & \multicolumn{2}{|c|}{7.94} & 33.15 & 22.84 \\
\hline
\end{tabular}

Although this dissolution test was praised by various pharmacopoeias it did not permit an evaluation of the form in which the drug was released during the test, keeping in mind that only one collection was performed at the end of a previously established time. In contrast, the use of dissolution profile, where various aliquots were collected and quantified during the test, made the construction of curves of "drug percentage versus time" possible. These curves allowed to achieve a series of parameters of useful dissolution kinetics in comparative studies of solid pharmaceutical form performances in vitro of (Ferraz, 1997). In this way, the evaluation of the dissolution profile could be auxiliary to the identification of formulations that presented potential risk in relation to the drug bioavailability (Shah et al., 1995). Furthermore, it is apart from being a useful tool in the development of formulations where it is possible to select those which present better performance in relation to the drug liberation (Abdou, 1995).
Evaluating the dissolved percentage curves versus time (Fig. 1), it could be observed that the analyzed products presented very distinct dissolution profiles, showing that the formulations were not homogeneous in relation to the in vitro drug liberation.

The comparison of dissolution profiles using the independent comparison method, where the dissolution efficiency values (DE) were submitted to statistical treatment (Table 3a,b and Table 4), allowed for the observation of formulations A, B, $\mathrm{C}, \mathrm{D}, \mathrm{E}, \mathrm{F}, \mathrm{G}$ and $\mathrm{H}$, for parameters of the described level $(\mathrm{P}=1.95 \mathrm{E}-23)$ and the value of $\mathrm{F}$ calculated at a level of significance of $5 \%(\mathrm{~F}=$ 101.6), between themselves on average were not equal and homogeneous.

The variance analysis allowed the following establishment: if the average populations were, or were not statistically equal. However, this type of analysis did not allow to detect if the averages were statistically different from the rest. 


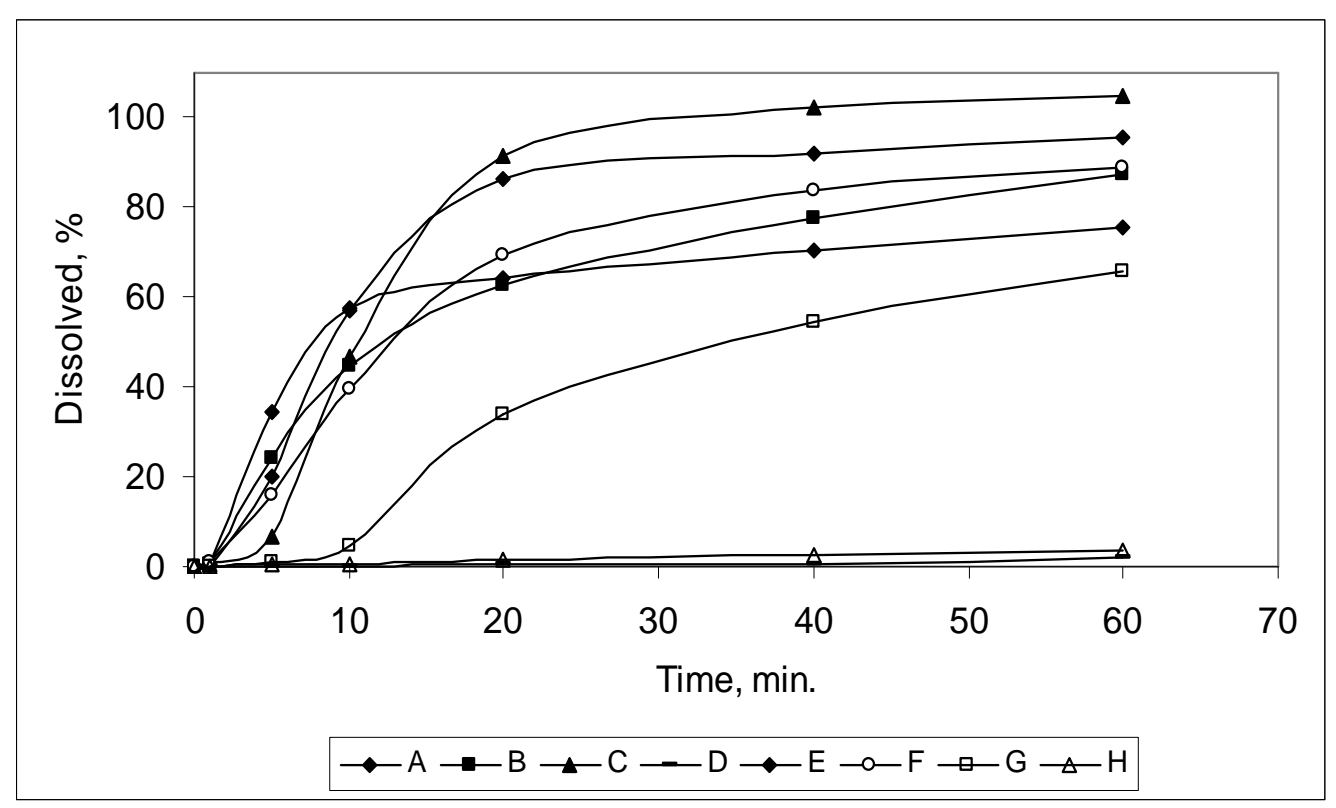

Figure 1 - Dissolution profile of chloramphenicol palmitate obtained from products A, B, C, D, E, $\mathrm{F}, \mathrm{G}$ and $\mathrm{H}$, for each time interval, in $\mathrm{HCl} 0.01 \mathrm{~N}$ environment. ${ }^{a}$ Each data point represents the mean of 12 units.

Table 3a - Individual values, average (M), Standard Deviation (SD) and Variation coefficient (VC) of Dissolution Efficiency (ED) for products A, B, C and D.

\begin{tabular}{ccccc}
\hline \multirow{2}{*}{ Vessels } & \multicolumn{4}{c}{ Dissolution Efficiency, \% } \\
\cline { 2 - 5 } & $\boldsymbol{A}$ & $\boldsymbol{B}$ & $\boldsymbol{C}$ & $\boldsymbol{D}$ \\
\hline 1 & 87 & 43 & 81 & 0 \\
2 & 87 & 75 & 81 & 0 \\
3 & 81 & 74 & 93 & 2 \\
4 & 72 & 78 & 74 & 0 \\
5 & 61 & 53 & 76 & 1 \\
6 & 73 & 60 & 80 & 0 \\
\hline M & 76.83 & 63.83 & 80.83 & 0.84 \\
S.D. & 10.13 & 14.11 & 6.62 & 167.33 \\
V.C. $(\%)$ & 13.18 & 22.10 & 8.18 & \\
\hline
\end{tabular}

Table 3b - Individual values, average (M), Standard Deviation (SD) and Variation coefficient (VC) of Dissolution Efficiency (ED) for products E, F, G and $\mathrm{H}$.

\begin{tabular}{ccccc}
\hline \multirow{2}{*}{ Vessels } & \multicolumn{4}{c}{ Dissolution Efficiency, $\%$} \\
\cline { 2 - 5 } & $\boldsymbol{E}$ & $\boldsymbol{F}$ & $\boldsymbol{G}$ & $\boldsymbol{H}$ \\
\hline 1 & 67 & 74 & 29 & 2 \\
2 & 72 & 74 & 24 & 2 \\
3 & 71 & 72 & 59 & 2 \\
4 & 64 & 74 & 42 & 2 \\
5 & 64 & 75 & 40 & 2 \\
6 & 65 & 73.00 & 37 & 2.00 \\
M & 67.17 & 2.19 & 38.50 & 0.00 \\
S.D. & 3.54 & 3.00 & 12.14 & 0.00 \\
V.C. $(\%)$ & 5.28 & & 31.55 & \\
\hline
\end{tabular}


Table 4 - Variance Analysis (ANOVA) of dissolution efficiency (DE) values for pharmaceutical products $\mathrm{A}, \mathrm{B}, \mathrm{C}, \mathrm{D}, \mathrm{E}, \mathrm{F}, \mathrm{G}$ and $\mathrm{H}$.

\begin{tabular}{lcccc}
\hline \multicolumn{1}{c}{ Variation source } & $\begin{array}{c}\text { Liberty } \\
\text { degrees }\end{array}$ & Square sum & Medium square & $\boldsymbol{F}^{\boldsymbol{a}}$ \\
\hline Between treatments & 45428.3 & 7 & 6498.7 & 101.6 \\
Within treatments & 2554.3 & 40 & 63.9 & \\
Total & 47982.7 & 47 & & \\
\hline
\end{tabular}

${ }^{a}$ Significant for $P>0.05 ; F_{\text {critical }}=7,34$.

The Tukey test permit to the establishment of a minimal significant difference (MSD), which was, a difference of sample averages which should be understood as being statistically significant, on a determined level. According to the Tukey test, two averages were statistically different whenever the value of absolute difference between them was equal to or superior to the minimum significant difference (MSD) value (Vieira, 1980). With the application of the Tukey test it was possible to observe that, with a level of significance of $5 \%$, the average of products $\mathrm{D}$ and $\mathrm{H}$ were are equal and significantly smaller than the average found for the other products (Table 5 and Fig. 2).

Solid drugs may exist as crystalline substances or amorphous particles without identifiable structure. The amorphous or crystalline character substance can affect the stability and activity of the drug within the formulation. The amorphous form often presents greater solubility, dissolution velocity and bioavailability than the crystalline structure, being that, in the amorphous state, the necessary energy for molecule separation is less than that of the crystalline form.

On the other hand, crystalline forms are more stable than amorphous forms (Ansel, 2000; Shargel, 1999; Grant, 2000). Crystalline substances can still exist in one or more forms. Common crystalline forms found in drugs are called polymorphous or solvates (Vippagunta et al., 2001). Solvates - also known as pseudopolymorphos - are crystalline forms that contain solvent molecules of a crystal nature. When the solvent is water, they are known as hydrates (Jozwiakowski, 2000; Carstensen, 2001). Polymorphs are different crystalline forms of the same pure substance, and possess the same chemical composition, but are different as to the internal structure of the crystal which is present in different conformations and/or arrangements and, as a result of this difference, the polymorphs present different physical-chemical properties (Grant, 1999; Shargel, 1999; Jozwiakowski, 2000; Vippagunta et al., 2001). The occurrence of polymorphs is very common, and it is estimated that one third of organic compounds present polymorphism.

Polymorphs can present differences considering their properties (Grant, 1999): in arrangement (refraction index, conductivity, hygroscopy); thermodynamics (melting point and sublimation, internal energy, enthalpy, entropy, solubility, etc.); spectroscopy (electronic transition, rotational transition, nuclear spin transition); kinetics (dissolution velocity, solid state reactions, stability); surface (superficial free energy, superficial tension, form); and mechanics (hardness, compatibility, compressivness, flow, etc).

Table 5 - Comparison of product dissolution profiles, using the independent model values of dissolution efficiency (DE), using the Tukey test and the minimum significant difference method (MSD =14.75).

\begin{tabular}{cc}
\hline Brands & $\begin{array}{c}\text { Homogeneous group } \\
\text { MSD/Tukey's Test }\end{array}$ \\
\hline A & B, C, E and F \\
B & A, E and F \\
C & A, E and F \\
D & H \\
E & A, B, C and F \\
$F$ & A, B, C and E \\
G & G \\
H & D \\
\hline
\end{tabular}




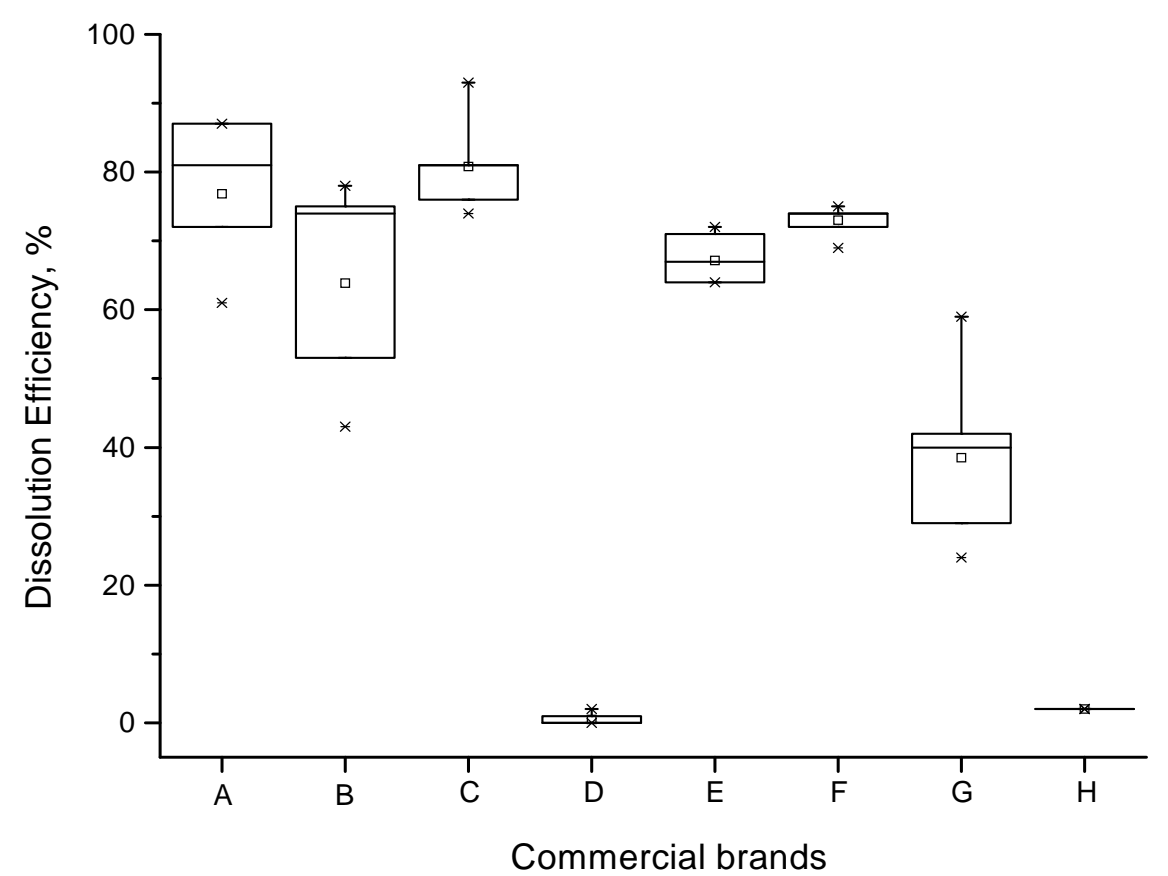

Figure 2 - Statistical comparison of the dissolution efficiency values (DE) for products A, B, C, $\mathrm{D}, \mathrm{E}, \mathrm{F}, \mathrm{G}$ and $\mathrm{H}$. The averages are indicated by cylinders in the boxes.

Concerning the existence of polymorphs, the most stable form generally presents lower solubility and consequently, the form which presents greater solubility is less stable, also referred to as metastable (Carstensen, 2001). For pharmaceutical products, these property differences between polymorphs and amorphous and crystalline forms directly affect the solubility and dissolution of the drug within its formulation, consequently affecting as the bioavailability as well (Byrn et al., 1995).

Three polymorphs of chloramphenicol palmitate have been described in literature: two crystalline forms - $\beta$ form (Form A) is the most stable and bio-inactive; the $\alpha$ form (Form B) is one of the metastable and bioactive, and amorphous forms. In the solid state, there is a transition from $\alpha$ form (Form B) to $\beta$ form (Form A), being that this process is irreversible. These crystalline forms differ in their physical-chemical properties (Banerjee et al., 1971; Miyamoto et al., 1973). Aguiar et al. (1967) demonstrated that the absorption of the $\alpha$ form (Form B) of chloramphenicol palmitate was significantly higher than the absorption of the $\alpha$ form (Form B) in humans. Serum levels were linearly proportional for the percentage of $\mathrm{B}$ form in mixtures containing both forms $(\mathrm{A} / \mathrm{B})$.

Anderson (1966) investigated thirteen preparations of oral administration containing chloramphenicol palmitate, where five of them predominantly presented the polymorph A. Aguiar and Zelmer (1969) demonstrated that the hydrolysis in vitro of the prodrug - chloramphenicol palmitate - of pancreatine was polymorph dependent, with significant hydrolysis of the $\alpha$ form (Form B) and little hydrolysis in the $\beta$ form (Form A). This difference in the solubility probably results in a difference in the hydrolysis rates and is responsible for the oral absorption differences. Borka and Bache-Hansen (1968) showed that, through spectroscopy of IV, the $\mathrm{H}$ bond of the $\mathrm{OH}$ group is stronger in the $\beta$ form (Form $A$ ) than in the $\alpha$ form (Form B), and the degree of rotation of this group is a determining factor in the solvation and/or hydrolysis of chloramphenicol palmitate.

Borka (1970), using differential thermal analysis and spectroscopy IV, identified the different polymorphs of chloramphenicol palmitate and studied its transition phase diagram. $\alpha$ form (Form B) - although metastable - has a superior stability, 
which together with its low solubility in water, guarantees stable formulations in solid forms or in suspension. Aguiar and Zelmer (1969), continuing their work, related the thermal behavior of chloramphenicol palmitate with the absorption data in vivo and concluded, through thermodynamic parameters, that when the free energy difference between polymorphs is high, alterations of absorption profiles can occur, however, if the free energy difference is low, there are no significant differences in absorption.

Banerjee et al. (1971) studied the absorption in vivo of the polymorph A and the amorphous form of suspensions of chloramphenicol palmitate and concluded that the absorption of the amorphous form is "significantly superior".

During the development of pharmaceutical formulations, the main objective is to formulate physically and chemically stable products as long as they present bioavailiblability. For drugs that present polymorphism, identification of the most thermodynamically stable polymorphs is recommended - less energy -, to assure the reproducibility in the bioavailability of the product during storage. There are situations where the development of amorphous crystalline metastable forms is justifiable due to therapeutic benefits. Such situations include those in which the highest dissolution and concentration are desired in order to obtain quick absorption and efficiency. If there are no justifiable reasons, the intentional development of a metastable form can generate risks for the patient. On the other hand, the existence of multiple crystalline modifications not recognized in a formulation can result in significant variations in dosage and compromise the bioavailability of the product.

\section{CONCLUSION}

Including as a reference, the literature data as well as data obtained experimentally, it could be concluded that significant differences existed in the liberation standards in vitro of chloramphenicol palmitate in solid pharmaceutical forms commercialized in Brazil; among the analyzed products, $\mathrm{G}$ and $\mathrm{H}$ were not approved by the criteria proposed by the American Pharmacopoeia (2004) and presented unacceptable performance in the dissolution test. Dissolution profiles presented by these products were equal on average, and significantly less than the average found for the other products involved.

During the development of pharmaceutical formulations - innovator or generic - was expected that chemically and physically stable products would be formulated, in such a way that they were bioavailable. For drugs that present polymorphism, identification of the polymorph most thermodynamically stable of the drug is recommended - less energy -, to assure the reproducibility in the bioavailability of the product during storage.

\section{ACNKOWLEDGEMENTS}

The authors would like to thank Ana Claudia Uehara e Maria Tereza L. Reis for technical assistance during this study.

\section{RESUMO}

O perfil de dissolução de formas farmacêuticas sólidas contendo palmitato de cloranfenicol 250 mg disponíveis no Brasil foi determinada pelo método da Farmacopéia Americana (United States Pharmacopeia, 2004) e comparado. Duas categorias de métodos para comparação dos perfis de dissolução foram utilizadas: ANOVA e modelo independente. Diferenças entre as formulações foram refletidas nos perfis de dissolução. A presença de polimorfos metaestáveis ou formas amorfas de palmitato de cloranfenicol pode ser responsável pelas variações na concentração do fármaco observada nas formulações.

\section{REFERENCES}

Abdou, H.M. (1995), Dissolution. In: GENARO, A.R. Remington: the science and practice of pharmacy. 19.ed. Easton: Mack publishing, v.1. 2077p.

Adams, E.; De Maesschalck, R.; De Spiegeller, B.; Heyden, Y.V.; Smeyers-Verbeke, J.; Massart, D.L. (2001), Evaluation of dissolution profiles using principal component analysis. Int. J. Pharm., Amsterdam, v.212, p.41-53.

Aguiar, A J.; Krc, Jr, J.; Kinkel, A W.; Samyn, J. (1967), Effect of polymorphism on the absorption of chloramphenicol from cloranphenicol palmitate. $J$. Pharm. Sci., Washington, v.57, n.7, p. 847-853. 
Aguiar, A J.; Zelmer, J. E. (1969), Dissolution behavior of polymorphs of chloramphenicol palmitate and mefenamic acid. J. Pharm. Sci., Washington, v.58, n.8, p.983-987.

Anderson, C. M. (1966) Australasian J. Pharm., v. 47, S44. apud: HALEBLIAN, J. and McCRONE. W. Pharmaceutical Applications of polymorphism. $J$. Pharm. Sci., Washington, v. 58, n. 8, p.911-929, 1969.

Ansel, H.C.; Popovich, N.G.; Allen JúnIOR, L.V. (2000), Farmacotécnica: formas farmacêuticas and Sistemas de liberação de fármacos. São Paulo: Premier. 568p.

Banerjee, S.; Bandyopadhyay, A.; Bhattacharjee, R. C.; Mukherjee, A. K.; Halder, A. K. (1971), Serum levels of chloraphenicol in children, rhesus monkeys, and cats after administration of chloramphenicol plamitate suspension. J. Pharm. Sci., Washington, v.60, n.1, p.153-155.

Bolton, S. (1990), Pharmaceutical statistics: practical and clinical applications. 2.ed. New York: Marcel Dekker. 646p. (Drugs and the pharmaceutical sciences, v.44).

Borka, L. and Bache-Hansen, K. (1968), Acta Pharm. Suecica, v. 5, p.525. apud: Maeda, T.; Takenaka, H.; Yamahira, Y.; Noguchi, T. Use of rabbits for absorption studies on polymorphs of chloramphenicol plamitate. Chem. Pharm. Bull, Tokyo, v.28, n.2, p.431-436, 1980.

Borka, L. (1970), Acta Pharm. Suecica, v.7, p.1. apud: HALEBLIAN, J.K. Characterization of habits and criystalline modification of solids and their pharmaceutical applications. J. Pharm. Sci., Washington, v. 64, n. 8, p. 1269-1288, 1975.

Byrn, S.; Pfeiffer, R.; Ganey, M.; Hoiberg, C.; Poochikian, G. (1995), Pharmaceutical solids: a styrategic approach to regulatory considerations. Pharm. Res., New York, v. 12, n.7, p. 945-954.

Carstensen, J.T. (2001), Polymorphism. In: Advanced Drug Delivery Reviews. New York: Marcel Dekker, p. 117-131.

Dressman, J.B.; Amidon, G.L.; Reppas, C.; Shah, V.P. (1998), Dissolution testing as a prognostic tool for oral drug absorpt: immediate release dosage forms. Pharm. Res., New York, v.15, n.1, p.11-22.

Ferraz, H.G. (1997), Avaliação biofarmacêutica in vitro $e$ in vivo (bioequivalência) de comprimidos de ampicilina $500 \mathrm{mg}$ comercializados no Brasil. São Paulo. 135p. Tese de Doutorado - Faculdade de Ciências Farmacêuticas - Universidade de São Paulo.

Glasko, A.J., Kinkel, A.W., Alegnani, W.C., Holmes, E.L. (1968), Clinical Pharmacol. Ther., v.9, p.472. apud: SALEH, A.K.; ALI, M.M Some formulation factors affecting disintegration and dissolution of chloramphenicol capsules. Acta Pharm. Suecica, v.9, p.563-572, 1972.
Grant, D.J.W. (1999) Theory and origin of polymorphism. In: BRITTAIN, H. G. ed. Polymorphism in Pharmaceutical Solids. New York: Marcel Dekker, p. 1-33.

Jozwiakowski, M.J. (2000), Alteration of solid state of the drug substance: polymorphs, solvates, and amorphous forms. In: LIU, R. ed. Water Insoluble Drug Formulation. Boca Raton: Interpharm / CRC Press, p. 525-568.

Juhl, R.P. (1973), Factors affecting release us medicaments from hard gelatin capsules. J. Pharm. Sci., Washington, v. 62, n.1, p.170.

Kapusnik-Uner, J.E.; Sandre, M.A; Chambers, H.F. Chemotherapy of microbial diseases. In: GOODMAN and GILMAN'S. The Pharmacological Basis of Therapeutics. 9 nd. Edn. New York: Mc Graw-Hill, 1996. p. 831-836.

Khan, K.A.; Rhodes, C.T. (1975), The concept of dissolution efficiency. J. Pharm. Pharmacol., Wallingford, v.27, p.48-49.

Miyamoto, M. A.; Kiyotaki, T.; Kisoh, N. A.; Mitsunaga, T.; Maeda T. (1973), Differential scanning calorimetry of chloranphenicol palmitate and the phase-transitional behavior of chloraphenicol palmitate observed during preparation of its oral suspension. Chem. and Pharm. Bull., Tokyo, v. 21, n.9, p.1857-1867.

Meredith, P.A. (1996), Generic Drugs: Therapeutic equivalence. Drug Safety, v.15, n.4, p.233-XXIV2.

Saleh, A.K.; Ali, M.M. (1972), Some formulation factors affecting disintegration and dissolution of chloramphenicol capsules. Acta Pharm. Suecica, v. 9, p.563-572.

Shah, V.P.; Noory, A.; Noory, C.; Mccullough, B.; Clarke, S.; Everett, R.; Naviasky, H.; Srinivasan, B.N.; Fortman, D.; Skelly, J.P. (1995), In vitro dissolution of sparingly water-soluble drug dosage forms. Int. J. Pharm., Amsterdam, v.125, p.99-106.

Shargel, L.; Yu, A.B.C. (1999), Applied biopharmaceutics and pharmacokinetics, 4ed., New York: McGraw-Hill, p. 129-167.

Singhal, D.; Curatolo, W. (2004), Drug polymorphism and dosage form design: a practical perspective. $A d v$. Drug Del. Rev., Amsterdam, v.56, p.335-347.

Skoug, J.W.; Halstead, G.W.; Theirs, D.L.; Freeman, J.E.; Fagam, D.T.; Rohs, B.R. (1996), Strategy for the development and validation of dissolution tests for solid oral dosage forms. Pharm. Technol., Eugene, v. 20, n.5, p.58-72.

United States Pharmacopeia: USP 27 (2004), Rockville: United States Pharmacopeial Convention.

United States. (1997), Department of Healthy and Human Services. Food and Drug Administration. Center for Drug Evaluation and Research. Guidance for Industry. Dissolution testing of immediate release solid oral dosage forms. Rockville: CMC, 1997. 17p. Available at: http://www.fda.gov/cder/guidance/ index.htm. Accessed in: 07 Jan 2002. 
Vieira, S. (1980), Introdução à Bioestatística. 3.ed. Rio de Janeiro: Campus. 196p.

Vippagunta, S.R.; Brittain, H.G.; Grant, D.J.W. (2001), Cristalline solids. Adv. Drug. Del. Rev., Amsterdam, v. 48 , p. 3-26.

Received: November 18, 2004;

Revised: July 17, 2005;

Accepted: September 12, 2006. 


\section{FOLHA}

EM

BRANCO 